\title{
Nitrogênio orgânico e químico na cultura da alface
}

\author{
Thomaz Figueiredo Lobo, Helio Grassi Filho, Eliana Pigozzi Biudes
}

Universidade Estadual Paulista - UNESP, Faculdade de Ciências Agronômicas, Botucatu, SP. E-mail: thomazfigueiredolobo@gmail.com

\section{Resumo}

Os resíduos orgânicos podem serem aproveitados para substituir os fertilizantes químicos, tendo em vista que estes resíduos apresentam todos os nutrientes essenciais para as plantas e melhorando as características físicas, químicas e biológicas do solo. O objetivo deste trabalho foi avaliar a eficiência na aplicação de nitrogênio orgânico e químico na nutrição e produção da alface. Este experimento foi conduzido na casa de vegetação com vaso de capacidade de 5 litros. O delineamento experimental foi realizado em blocos casualizados constituídos por seis tratamentos e cinco repetições em dois ciclos de cultivo da alface crespa da variedade Lucy Brown, assim definido: T0 - sem adubação nitrogenada; T1 - 0,54 g de $\mathrm{N}$ (ureia) por planta dividida em três vezes (7, 14 e 28 dias de transplante), T2 - 0,27 g de N (Composto orgânico) e 0,27 g de N (ureia) dividido em três vezes por planta (7, 14 e 28 dias de transplante); T3 - 0,54 g de N (composto orgânico) por planta; T4 - 0,81 g de N (composto orgânico) por planta; T5 - 1,08 g de N (composto orgânico) por planta. Os tratamentos T1, T2 e T3 representam $100 \%$ da recomendação de N pela alface e os tratamentos T4 e T5 representam 150 e 200\%, respectivamente. Na produção do primeiro ciclo da alface os tratamentos T4 e T5 que receberam maiores quantidades do composto orgânico, apresentaram uma produção de massa verde superior aos demais tratamentos. No segundo ciclo da alface todos os tratamentos que receberam a adubação orgânica obtiveram uma produção de massa verde superior que os tratamentos que não foram adubados com o composto.

Palavras - chave: compostagem; Lucy Brown; fertilizante; nutrição mineral de plantas; Lactura Sativa.

\section{Organic and chemical nitrogen in lettuce culture}

\begin{abstract}
Organic residues can replace chemical fertilizers, showing all essential nutrients for plants improving the physical, chemical and biological soil characteristics. We evaluated the efficiency of organic and chemical nitrogen in the nutrition and production of lettuce. This experiment was carried out in a greenhouse with a 5-liter pot. The experimental design was randomized blocks with six treatments and five repetitions in two cycles of green-leaf lettuce from Lucy Brown variety, as defined: T0 - without nitrogen fertilization; T1 - 0.54 $\mathrm{g}$ of $\mathrm{N}$ (urea) per plant divided into three times (7, 14 and 28 days of transplant), T2 - $0.27 \mathrm{~g}$ of $\mathrm{N}$ (organic compound) and $0.27 \mathrm{~g}$ of $\mathrm{N}$ (urea) divided into three times per plant (7, 14 and 28 days of transplant); T3 $0.54 \mathrm{~g}$ of $\mathrm{N}$ (organic compound) per plant; T4 - $0.81 \mathrm{~g}$ of $\mathrm{N}$ (organic compound) per plant; T5 - $1.08 \mathrm{~g}$ of $\mathrm{N}$ (organic compound) per plant. T1, T2, and T3 treatments represent $100 \%$ of the $\mathrm{N}$ recommendation for lettuce and the T4 and T5 treatments represent 150 and 200\%, respectively. In the first cycle of lettuce, the T4 and T5 treatments with higher amounts of organic compounds led to an increase of green mass production comparing to other treatments. In the second cycle of lettuce, all treatments that received organic fertilization obtained a higher green mass production than treatments with no compound.

Keywords: composting; Lucy Brown; fertilizer; mineral plant nutrition; Lactura Sativa.
\end{abstract}




\section{Introdução}

$\mathrm{O} N$ é um dos nutrientes limitantes para o desenvolvimento da alface, segundo Beninni et al. (2005), sendo o segundo nutriente químico mais absorvido por esta planta, tendo o $\mathrm{K} \mathrm{O}$ nutriente mais absorvido. Este é um dos mais importantes macros nutrientes primários essencial às plantas, participando da formação de proteínas, aminoácidos e de outros compostos importantes para o metabolismo e crescimento das plantas (TAIZ; ZEIGER, 2013). A adubação nitrogenada recomendada para a alface está em torno de 100 a $130 \mathrm{Kg} \mathrm{ha}^{-1}$ de $\mathrm{N}$ ou 40 a $60 \mathrm{t} \mathrm{ha}^{-1}$ de esterco de curral para (RAIJ et al., 1997).

O aumento do custo de fertilizantes minerais e a crescente poluição ambiental fazem do uso de resíduos orgânicos na agricultura uma opção atrativa do ponto de vista econômico, em razão da ciclagem de C e nutrientes (SILVA et al., 2010). Isto gera aumento na demanda por pesquisa para avaliar a viabilidade técnica e econômica dessa utilização (MELLO; VITTI, 2002).

Assim a adubação orgânica, além de ser um dos métodos de adubação mais viável para o produtor, proporciona grandes benefícios para a produção, pois melhora as características físicas do solo como as biológicas, promovendo a diminuição do processo erosivo, maior disponibilidade de nutrientes, agregando maior quantidade de partículas, garantindo maior retenção de água e menor variação de temperatura no solo (SANTIAGO; ROSSETTO, 2009).

Os adubos orgânicos são utilizados principalmente pelo fornecimento de matéria orgânica como fonte de energia e nutrientes para os organismos participando do ciclo biológico, proporcionando ao solo um estado dinâmico e exercendo importante função em sua fertilidade, promovendo $\mathrm{o}$ aumento da porosidade $\mathrm{e}$ aeração, evitando perdas por escoamento superficial (SILVA, 2012).

Os resíduos orgânicos com relação $\mathrm{C} / \mathrm{N}$ menores, decompõem-se mais rapidamente do que os resíduos que apresenta uma maior relação $\mathrm{C} / \mathrm{N}$. A relação $\mathrm{C} / \mathrm{N}$ ideal para iniciar a compostagem é 30/1, neste processo se utiliza resíduos orgânico de relação superior e inferior a 30/1 (BARREIRA et al., 2009).

$\mathrm{O}$ esterco de galinha é rico em $\mathrm{N}$, elemento essencial para o desenvolvimento e produção das plantas, este vem misturado com maravalha, produto que é utilizado para fazer uma "cama" para as aves. Desta forma toda a maravalha que apresenta uma relação $\mathrm{C} / \mathrm{N}$ elevada demora mais para a decomposição do que o esterco de galinha que contém uma relação $\mathrm{C} / \mathrm{N}$ baixa se decompõe mais rapidamente. A compostagem é um processo fundamental para o aproveitamento da cama de aviário, tornando-se uma ótima opção de adubação para várias culturas, além de fornecer macro e micro nutrientes para as plantas, auxiliando no aumento da matéria orgânica no solo (AGNOL, 2013).

A vantagem do uso de adubo orgânico em relação à aplicação de fertilizantes químicos é a liberação gradual dos nutrientes à medida que são demandados para o crescimento da planta (LIMA et al., 2014).

A adubação orgânica com esterco de animais e compostos orgânicos tem sido amplamente utilizada na produção de alface, tendo como objetivo a redução de quantidades de fertilizantes químicos e melhor qualidade física, química e biológica do solo (PEIXOTO FILHO et al., 2013).

Segundo Silva et al. (2010) a adubação orgânica incrementa a produtividade, e produz plantas com características qualitativas melhores que as cultivadas exclusivamente com adubos minerais podendo, portanto, exercer influência sobre a qualidade nutricional da alface. Sua utilização tem proporcionado aumento de produção e no teor de nutrientes em plantas de alface (RODRIGUES; CASALI, 1998).

O objetivo do trabalho foi observar a melhor maneira de suprir o nitrogênio químico ou orgânico nos parâmetros nutricionais e produtivos em dois ciclos consecutivos da cultura da alface.

\section{Material e Métodos}

O experimento foi conduzido na casa de vegetação do Departamento de Ciência do Solo da Faculdade de Ciências Agronômicas de Botucatu, tendo como coordenadas geográficas (2250'S, 4822' W, altitude $815 \mathrm{~m}$ ).

O solo utilizado no experimento foi Latossolo Vermelho Distrófico (SANTOS, 2013). As características de fertilidade do solo antes de iniciar o experimento obtiveram os seguintes resultados na análise química: $\mathrm{pH}\left(\mathrm{CaCl}_{2}\right)=4,1$; matéria orgânica $=23 \mathrm{~g} \mathrm{dm}^{-3} ; \mathrm{P}=2 \mathrm{mg} \mathrm{dm}^{-3} ; \mathrm{V} \%=$ 6; e os valores de $\mathrm{H}+\mathrm{Al}=57 \mathrm{mmol}_{\mathrm{c}} \mathrm{dm}^{-3} ; \mathrm{Al}=11$ $\mathrm{mmol}_{\mathrm{c}} \mathrm{dm}^{-3} ; \mathrm{K}=0,4 \mathrm{mmol}_{\mathrm{c}} \mathrm{dm}^{-3} ; \mathrm{Ca}=2 \mathrm{mmol}_{\mathrm{c}}$ $\mathrm{dm}^{-3} ; \mathrm{Mg}=1 \mathrm{mmol}_{\mathrm{c}} \mathrm{dm}^{-3} ; \mathrm{SB}=3,4 \mathrm{mmol}_{\mathrm{c}} \mathrm{dm}^{-3}$; CTC $=60,4 \mathrm{mmol}_{\mathrm{c}} \mathrm{dm}^{-3}$ e os micronutrientes: $\mathrm{B}$; 
$\mathrm{Cu}$; Fe; $\mathrm{Mn}$; $\mathrm{Zn}$ expressos em $\mathrm{mg} \mathrm{dm}^{-3}$ de: 0,30; 0,$7 ; 77 ; 0,4$ e 0,1 , respectivamente.

O experimento foi conduzido em Vasos com capacidade de 5 litros. Foi utilizado a alface crespa da variedade Lucy Brown em dois ciclos de cultivo.

O delineamento experimental foi em blocos casualisados com 5 repetições, os tratamentos foram assim definidos: TO - sem adubação nitrogenada; T1 - 0,54 g de N (ureia) por planta dividida em três vezes $(7,14$ e 28 dias de transplante); $\mathrm{T} 2-0,27 \mathrm{~g}$ de $\mathrm{N}$ (composto orgânico) e $0,27 \mathrm{~g}$ de $\mathrm{N}$ (ureia) dividido em três vezes por planta (7, 14 e 28 dias de transplante); T3 - 0,54 g de N (composto orgânico) por planta; T4 - 0,81 g de N (composto orgânico) por planta; T5 - 1,08 g de N (composto orgânico) por planta.
Os tratamentos T1, T2 e T3 foram referentes a quantidade $100 \%$ de $\mathrm{N}$ pelas plantas segundo a recomendação do estado de São Paulo (RAIJ et al., 1997).

O composto orgânico utilizado no experimento foi obtido através da compostagem com cavaco de eucalipto triturado (77\%) e esterco de galinha (23\%). Quando iniciou a compostagem a relação $\mathrm{C} / \mathrm{N}$ foi calculada para 33/1. O cálculo para a quantidade do composto foi efetuado baseado na quantidade necessária de $\mathrm{N}$, considerando uma mineralização de $20 \%$ de $N$ (BRASIL, 2006). As características químicas do composto orgânico utilizado neste experimento apresentam na Tabela 1.

Tabela 1. Característica química do composto orgânico

\begin{tabular}{|c|c|c|c|c|c|c|c|c|c|c|c|c|c|}
\hline$N$ & $\mathrm{P}_{2} \mathrm{O}_{5}$ & $\mathrm{~K}_{2} \mathrm{O}$ & $\mathrm{C}$ & $\mathrm{Ca}$ & $\mathrm{Mg}$ & $\mathrm{S}$ & $\mathrm{Na}$ & $\mathrm{Cu}$ & $\mathrm{Fe}$ & $\mathrm{Mn}$ & $\mathrm{Zn}$ & $\mathrm{C} / \mathrm{N}$ & $\mathrm{pH}$ \\
\hline & & \multicolumn{3}{|c|}{ \% na base úmida } & \multicolumn{9}{|c|}{$\mathrm{mg} \mathrm{kg}^{-1}$ na base úmida } \\
\hline 1,6 & 3,2 & 1,1 & 27 & 6,4 & 0,5 & 1,8 & 1656 & 80 & 15262 & 566 & 292 & 17 & 6,9 \\
\hline
\end{tabular}

Diante da necessidade de calagem, a aplicação de calcário em todo o volume do solo foi realizada 30 dias antes do transplante das mudas, para os vasos após a aplicação do calcário foi irrigado até a capacidade de campo do solo para ocorrer a reação do calcário e estes vasos foram incubados para evitar a evaporação da água, pois o alface necessita a elevação $\mathrm{V} \%$ para 80 (RAlJ et al., 1997), utilizou o calcário dolomítico de PRNT 90\%, com isto cada vaso de 5 litros foi usado $12,25 \mathrm{~g}$. A adubação química básica constituiu-se de $150 \mathrm{ppm}$ de $\mathrm{P}$ e $50 \mathrm{ppm}$ de $\mathrm{K}, 9.8 \mathrm{~g}$ de superfosfato simples $\left(18 \mathrm{~g} \mathrm{~kg}^{-1}\right.$ $\mathrm{P}_{2} \mathrm{O}_{5}$ ) e 0,5 gramas de Cloreto de Potássio (60 g $\mathrm{kg}^{-1} \mathrm{~K}_{2} \mathrm{O}$ ), respectivamente por vaso.

Os tratamentos que foram adubados com o composto orgânico T2, T3, T4 e T5 receberam $94,188,282$ e 376 gr por vaso do composto orgânico, respectivamente. Esta adubação foi efetuada antes do plantio.

Por ocasião da aplicação da adubação de plantio, foram transplantadas mudas do cultivar Lucy Brown da alface crespa com 30 dias de semeadura, adquiridas por uma casa de revendas de produtos agrícolas. Para cada vaso foi transplantada uma muda no centro, com 2,5 centímetros de profundidade, não ocorreu perdas de mudas no transplantio.

O manejo da irrigação foi efetuado em função da evapotranspiração de agua do Tanque classe A que estava instalado dentro da casa de vegetação.

Os parâmetros avaliados neste experimento foram: produção de massa seca e massa fresca por planta e exportação de nutrientes. A produção de massa fresca total foi determinada através da pesagem das plantas de alface logo após o corte rente do solo. Para a determinação da massa seca foram coletadas 5 folhas de alface de cada parcela esta foi pesada, em seguida lavadas com água comum, com detergente e deionizada. As folhas foram condicionadas em sacos de papeis identificados e posteriormente foi encaminhado em uma estufa de ventilação forçadas a $650 \mathrm{C}$, até obter massa constante (72 horas). Após este período pesou novamente tendo a massa seca. Com o peso úmido e o peso seco calculou-se a porcentagem de matéria seca de cada tratamento. Tendo a produção das 5 folhas de massa verde e a produção de 5 folhas de massa seca por regra de três calcula a produção de massa seca por planta. As mesmas plantas colhidas para a matéria seca foram moídas e acondicionado em um saco de papel. As amostras foram encaminhadas para analises de nutrientes seguindo a metodologia descrita por (MALAVOLTA et al., 1997). A exportação de nutrientes foi calculada multiplicando os teores com a produção de matéria seca. 
Os resultados foram submetidos a análise de variância e a comparação de médias com $5 \%$ de significância pelo teste de Scott Knott.

\section{Resultados e Discussão}

Na produção do primeiro ciclo as alfaces que foram adubadas com maiores quantidades do composto orgânico 282 gr e 376 gr por planta apresentaram uma produção de massa verde superior aos demais tratamentos. As alfaces que foi utilizado $188 \mathrm{gr}$ do composto por planta e as plantas adubadas com $94 \mathrm{gr}$ do composto com suplementação de uréia obtiveram uma maior produção de massa verde em relação as plantas que foram adubadas somente com uréia e que não foi utilizado $N$. As alfaces que foram adubadas com $\mathrm{N}$ proveniente da uréia obteve uma maior produção de massa verde que as alfaces que não recebeu nenhuma fonte de $\mathrm{N}$ (Tabela 2). Segundo Silva et al. (2010) comprovaram que a utilização de composto orgânico supriu as necessidades de $\mathrm{N}$ na dose de $30 \mathrm{t} \mathrm{ha}^{-1}$ para a alface veronica, dispensando a adubação com N mineral. Sediyama et al. (2016) observaram um aumento na produtividade da alface com o uso de fertilizantes orgânicos em $42 \%$ comparado com o não uso deste fertilizante. Queiroz et al. (2017) testaram doses de fertilizantes organo minerais $(0,400,800,1.200 \mathrm{e}$ $1.600 \mathrm{~kg} \mathrm{ha}^{-1}$ ) e foi constatado que a maior dose utilizado foi que obteve maior produtividade de alface.

No segundo ciclo da alface todos os tratamentos que receberam a adubação orgânica obtiveram uma produção de massa verde superior que os tratamentos que não foram adubados com o composto (Tabela 2). Peixoto Filho et al. (2013) comparando a adubação orgânica com a mineral na alface verificou que a adubações com resíduos orgânicos aumentou a produção de massa fresca a partir do 3으 ciclo e nos dois primeiros ciclos a produção não diferiu estatisticamente.

Tabela 2. Produção de massa verde e matéria seca dos tratamentos (Production of green mass and dry matter of treatments).

\begin{tabular}{ccccc}
\hline \multirow{2}{*}{ Tratamentos } & \multicolumn{2}{c}{$\begin{array}{c}\text { Produção Massa Verde } \\
\text { (g planta }\end{array}$} & \multicolumn{2}{c}{$\begin{array}{c}\text { Produção Massa Seca } \\
\text { (g planta }\end{array}$} \\
\cline { 2 - 5 } )
\end{tabular}

*Médias seguidas pela mesma letra na coluna não diferem estatisticamente entre si pelo teste de Scott Knott (5\%) (means followed by the same letter in column do not differ significantly, Scott Knott 5\%).

No primeiro ciclo os tratamentos que receberam compostos orgânicos foram superiores em produção de massa seca que os tratamentos que não receberam adubações orgânicas. A alface adubada com $\mathrm{N}$ químico obteve uma maior produção de matéria seca que o tratamento que não foi utilizado N. O tratamento que recebeu a maior dose do composto orgânico obteve a maior produção de massa seca que os outros tratamentos (Tabela 2).

No segundo ciclo não houve diferença do tratamento com $\mathrm{N}$ químico e sem o $\mathrm{N}$. Os tratamentos que foram adubados com composto orgânico obtiveram uma produção de massa seca superior que os tratamentos que não utilizou o composto orgânico. $\mathrm{O}$ tratamento que recebeu a 
maior dose do composto orgânico foi superior a todos em matéria seca (Tabela 2). Steiner et al. (2012) testando fonte de $\mathrm{N}$ para a cultura da alface utilizando uréia e adubos orgânicos (dejetos suínos e cama de aviário) não foi verificado diferenças significativas na produção de massa seca. Quando se trabalha com adubos orgânicos a mineralização do $\mathrm{N}$ irá depender muito das condições climáticas, em vista disto se encontra experimentos que ocorra diferenças significativas e outros não pelo fata de ter ocorrido uma maior ou menor mineralização.

As plantas que recebeu a maior quantidade do composto orgânico apresentaram um maior acúmulo de $\mathrm{N}$ que os demais. As alfaces que foram adubados com $\mathrm{N}$ orgânico e mineral e as que foram adubadas com $150 \%$ da quantidade de $\mathrm{N}$ proveniente do composto orgânico acumularam uma maior quantidade de $\mathrm{N}$ em relação as plantas que não foram adubadas com N, as plantas que foram adubadas com $100 \%$ $\mathrm{N}$ químico e as plantas que receberam $100 \% \mathrm{~N}$ orgânico (Tabela 3). Quando foi adubado $50 \%$ do $\mathrm{N}$ orgânico e $50 \% \mathrm{~N}$ químico, obteve maior acumulo de $\mathrm{N}$ do que $100 \% \mathrm{~N}$ orgânico, isto pode ser explicado pelo $\mathrm{N}$ químico ter ajudado na mineralização do N orgânico (LOBO; GRASSI FILHO, 2009).

No segundo ciclo as plantas que foram adubadas com a maior dose do composto orgânico T5 obtiveram maior acúmulo. As plantas que não receberam adubação com composto orgânico acumularam menor quantidade de $\mathrm{N}$ (Tabela 4).

As alfaces do primeiro ciclo as plantas adubadas com adubação orgânica apresentaram maior teor e acúmulo de $\mathrm{P}$ nas folhas, plantas que foram adubadas com maior quantidade do composto orgânico (T5) obteve maior acumulo de $P$ que as outras plantas (Tabela 3). O composto utilizado neste experimento por ser rico em $\mathrm{P}\left(3,2 \%\right.$ de $\left.\mathrm{P}_{2} \mathrm{O}_{5}\right)$, devido a isto proporcionou grande diferença no seu acúmulo. No segundo ciclo observa-se na Tabela 4 que as alfaces (T5) acumulou maior quantidade de $\mathrm{P}$ e plantas que não foram realizadas adubação orgânica acumularam menos $\mathrm{P}$ nas folhas.

Santos et al., (2001), comparando adubações orgânica e mineral sobre a alface, observaram que $o$ uso do adubo orgânico aumentou os teores de base como o fósforo e a capacidade de troca de cátions do solo e que a continua liberação de $\mathrm{N}$ pela mineralização do material orgânico, ajustou-se melhor às necessidades da alface do que o fornecimento de formulações solúveis prontamente disponíveis. Souza et al. (2005) verificaram que o aumento da dose do composto orgânico proporcionou um maior teor de $\mathrm{P}$ nas folhas de alface, além do composto orgânico apresentar $P$ pode também diminuir a fixação do $P$ pelos solos altamente intemperizados melhorando desta forma a sua disponibilidade.

No primeiro ciclo as plantas que foram adubadas com a maior quantidade de composto orgânico acumularam maior quantidade de $\mathrm{K}$. As plantas que foram adubadas com 150\% da necessidade de $\mathrm{N}$, proveniente do composto orgânico acumularam maior quantidade de $\mathrm{K}$ que as plantas que receberam $100 \%$ do $\mathrm{N}$ independente da fonte e as plantas que não receberam $N$. As alfaces que não foram efetuados a adubação orgânica (T0 e T1) acumularam menor quantidade de $\mathrm{K}$ que as plantas que foram feitas esta adubação (Tabela 3). As cargas negativas provenientes da adubação com o composto orgânico podem ter retido o $\mathrm{K}$ não deixado que este ion seja lixiviado e o próprio composto apresentava um teor de 1,1\% de $\mathrm{K}_{2} \mathrm{O}$. Na menor dose do composto $\mathrm{T} 2$ foi acrescentado 94 gramas de $\mathrm{K}$ que representaria $1,15 \mathrm{~g}$ de $\mathrm{K}_{2} \mathrm{O}$. Resende et al. (2009), afirmam que há efeito significativo e complementar na absorção de $\mathrm{N}$ e $\mathrm{K}$, que o importante é a necessidade de um adequado nível de $\mathrm{K}$ para incrementar a produtividade, com adição de $\mathrm{N}$.

No segundo ciclo o tratamento T5 de maior dose do composto orgânico acumulou mais $\mathrm{K}$ que os demais tratamentos e os tratamentos que não receberam adubação orgânica apresentaram menor acumulo de $\mathrm{K}$ (Tabela 4).

No primeiro e no segundo ciclo, observase nas Tabelas 3 e 4 que os tratamentos que receberam adubações com o composto orgânico apresentaram um maior acumulo de Ca que os tratamentos que não receberam adubação orgânica.

O Mg no primeiro ciclo apresentou um maior acúmulo para os tratamentos T2, T4 e T5 em relação aos demais tratamentos. 0 tratamento sem $\mathrm{N}$ acumulou menos $\mathrm{Mg}$ que os demais tratamentos (Tabela 3). Koo e Reese (1977) afirmam que o $\mathrm{N}$ e o $\mathrm{Mg}$ na folha relacionam-se positivamente, havendo uma relação sinérgica entre eles.

Os tratamentos que foram adubados com composto orgânico no segundo ciclo obtiveram 
um maior acúmulo de $\mathrm{Mg}$ que os demais tratamentos (Tabela 4).

As plantas adubadas com maior dose de composto orgânico acumularam mais $S$ que as outras plantas de alface. As alfaces adubadas com composto orgânico acumularam mais $S$ que as plantas que não receberam esta adubação. As plantas adubadas com $100 \% \mathrm{~N}$, proveniente da uréia acumulou mais $S$ que plantas que não foram adubadas com $\mathrm{N}$ (Tabela 3). Maior absorção de $\mathrm{S}$ com a aplicação de $\mathrm{N}$ pode ser explicada em parte pelo efeito sinérgico existente, sendo relatado por (SHARMA et al., 1994).

No segundo ciclo as alfaces que foram adubadas com a maior dose do composto orgânico (T5) acumulou mais $\mathrm{S}$ que as outras plantas de alface e as plantas que não foram adubadas com composto orgânico acumularam menos $\mathrm{S}$ que a adubação com composto orgânico (Tabela 4).

No primeiro e no segundo ciclo as plantas adubadas com $200 \%$ da necessidade de $\mathrm{N}$ proveniente do composto orgânico obtiveram maior acúmulo de $\mathrm{Cu}$ e os tratamentos que não receberam adubação orgânica apresentaram um acúmulo menor (Tabelas 3 e 4).

O acúmulo de Fe no primeiro ciclo do cultivo as alfaces que receberam maior dosagem do composto orgânico T4 e T5 acumularam maior quantidade deste nutriente que as outras alfaces e as plantas que não foram feitas adubações orgânicas acumularam menor quantidade de Fe (Tabela 3). No segundo ciclo do cultivo as alfaces de maior dose do composto orgânico acumulou mais Fe que as demais plantas e as plantas que não receberam adubação com composto orgânico acumularam menos $\mathrm{Fe}$ do que as que foram efetuadas esta adubação (Tabela 4).

No primeiro ciclo os tratamentos T3 e T4 obtiveram um maior acumulo de $\mathrm{Mn}$ que os demais tratamentos. Os tratamentos que não receberam adubação do composto orgânico (T0 e T1) acumularam menos $\mathrm{Mn}$ que os tratamentos que foram adubados com o composto orgânico
(Tabela 3). As plantas que foram adubadas com maior dose do composto orgânico acumularam menor quantidade de $\mathrm{Mn}$ que as plantas adubadas dom $100 \%$ e $150 \%$ da necessidade da cultura em $\mathrm{N}$ proveniente com o composto orgânico. O decréscimo de $\mathrm{Mn}$ na maior dose do composto orgânico pode estar relacionado com o acumulo de $\mathrm{Fe}$, isto porque quando a planta absorve uma quantidade maior de $\mathrm{Fe}$ pode diminuir a absorção de $\mathrm{Mn}$.

No segundo ciclo os tratamentos que foram adubados com composto orgânico acumularam mais $\mathrm{Mn}$ que os tratamentos que não receberam este tipo de adubação (Tabela 4).

No primeiro ciclo as plantas adubadas com $200 \%$ N proveniente do composto orgânico acumularam uma maior quantidade de $\mathrm{Zn}$ que as outras plantas. Os tratamentos T3 e T4 acumularam mais $\mathrm{Zn}$ que os tratamentos T0, T1 e T2. Os tratamentos que não receberam adubação com o composto orgânico acumularam menos Zn que os demais tratamentos (Tabela 3).

No segundo ciclo o tratamento de maior dose do composto orgânico acumulou mais Zn que os demais tratamentos. Os tratamentos que não foram adubados com o composto orgânico acumularam menos $\mathrm{Zn}$ que os tratamentos que receberam este tipo de adubação (Tabela 4).

Lobo et al. (2013) observaram que o aumento da dose de composto orgânico com lodo de esgoto no solo obtiveram um maior teor no solo de $\mathrm{Cu}, \mathrm{Fe}, \mathrm{Mn}$ e $\mathrm{Zn}$ na profundidade de 0 a $20 \mathrm{~cm}$. Lobo et al. (2019) verificaram que aumentando a dose de composto orgânico houve um incremento na exportação de $\mathrm{Cu}$, Fe, Mn e $\mathrm{Zn}$ na cultura do girassol. Em vista disto acredita-se que os compostos orgânicos além dos diversos benefícios ao solo também pode ser uma fonte de micronutrientes que a produção de fertilizantes concentrados muitas vezes não apresenta. Com isto a produtividade das culturas pode estas limitadas com os micronutrientes. 
Tabela 3. Acúmulo de nutrientes na alface (Nutrient accumulation in lettuce) no primeiro ciclo.

\begin{tabular}{cccccccccccc}
$\begin{array}{c}\text { Tratamentos } \\
\text { 19Ciclo }\end{array}$ & $\mathbf{N}$ & $\mathbf{P}$ & $\mathbf{K}$ & $\mathbf{C a}$ & $\mathbf{M g}$ & $\mathbf{S}$ & $\mathbf{C u}$ & $\mathrm{Fe}$ & $\mathbf{M n}$ & $\mathrm{Zn}$ \\
\hline T0 & $0,23 \mathrm{c}$ & $0,05 \mathrm{c}$ & $0,70 \mathrm{~d}$ & $0,13 \mathrm{~b}$ & $0,05 \mathrm{c}$ & $0,03 \mathrm{~d}$ & $0,05 \mathrm{c}$ & $0,23 \mathrm{c}$ & $0,10 \mathrm{c}$ & $0,36 \mathrm{~d}$ \\
T1 & $2,18 \mathrm{c}$ & $0,13 \mathrm{c}$ & $3,58 \mathrm{~d}$ & $0,97 \mathrm{~b}$ & $0,42 \mathrm{~b}$ & $0,12 \mathrm{c}$ & $0,15 \mathrm{c}$ & $0,74 \mathrm{c}$ & $0,75 \mathrm{c}$ & $1,02 \mathrm{~d}$ \\
T2 & $4,02 \mathrm{~b}$ & $0,37 \mathrm{~b}$ & $13,16 \mathrm{c}$ & $2,14 \mathrm{a}$ & $0,67 \mathrm{a}$ & $0,24 \mathrm{~b}$ & $0,60 \mathrm{~b}$ & $1,55 \mathrm{~b}$ & $2,55 \mathrm{~b}$ & $3,00 \mathrm{c}$ \\
T3 & $2,94 \mathrm{c}$ & $0,39 \mathrm{~b}$ & $11,42 \mathrm{c}$ & $2,00 \mathrm{a}$ & $0,49 \mathrm{~b}$ & $0,19 \mathrm{~b}$ & $0,49 \mathrm{~b}$ & $1,58 \mathrm{~b}$ & $3,48 \mathrm{a}$ & $4,67 \mathrm{~b}$ \\
T4 & $4,59 \mathrm{~b}$ & $0,41 \mathrm{~b}$ & $16,68 \mathrm{~b}$ & $2,17 \mathrm{a}$ & $0,67 \mathrm{a}$ & $0,23 \mathrm{~b}$ & $0,62 \mathrm{~b}$ & $2,28 \mathrm{a}$ & $3,25 \mathrm{a}$ & $5,04 \mathrm{~b}$ \\
T5 & $6,31 \mathrm{a}$ & $0,54 \mathrm{a}$ & $24,95 \mathrm{a}$ & $2,02 \mathrm{a}$ & $0,77 \mathrm{a}$ & $0,30 \mathrm{a}$ & $0,81 \mathrm{a}$ & $2,15 \mathrm{a}$ & $2,40 \mathrm{~b}$ & $9,67 \mathrm{a}$ \\
\hline F & $35,87^{*}$ & $30,21^{*}$ & $69,63 *$ & $26,09 *$ & $25,66^{*}$ & $24,16 *$ & $35,23 *$ & $19,40 *$ & $36,48 *$ & $65,23 *$ \\
Média & 3,38 & 0,31 & 11,75 & 1,57 & 51,06 & 0,183 & 0,45 & 1,42 & 2,09 & 3,96 \\
CV (\%) & 23,18 & 24,34 & 20,13 & 23,28 & 23,89 & 23,89 & 24,43 & 28,51 & 24,24 & 23,55 \\
\hline
\end{tabular}

Tabela 4-Acúmulo de nutrientes do alface no segundo ciclo

\begin{tabular}{ccccccccccc}
\hline $\begin{array}{c}\text { Tratamentos } \\
\text { 2oCiclo }\end{array}$ & $\mathbf{N}$ & $\mathbf{P}$ & $\mathbf{K}$ & $\begin{array}{c}\text { Ca } \\
\text { g planta }^{-1}\end{array}$ & $\mathbf{M g}$ & $\mathbf{S}$ & $\mathbf{C u}$ & $\begin{array}{c}\mathbf{F e} \\
\text { mg planta }^{-1}\end{array}$ & Zn \\
\hline T0 & $0,17 \mathrm{c}$ & $0,02 \mathrm{c}$ & $0,67 \mathrm{c}$ & $0,07 \mathrm{~b}$ & $0,02 \mathrm{~b}$ & $0,01 \mathrm{c}$ & $0,05 \mathrm{c}$ & $0,71 \mathrm{c}$ & $0,47 \mathrm{~b}$ & $0,22 \mathrm{c}$ \\
T1 & $0,87 \mathrm{c}$ & $0,05 \mathrm{c}$ & $2,42 \mathrm{c}$ & $0,35 \mathrm{~b}$ & $0,15 \mathrm{~b}$ & $0,04 \mathrm{c}$ & $0,22 \mathrm{c}$ & $3,23 \mathrm{c}$ & $3,12 \mathrm{~b}$ & $0,68 \mathrm{c}$ \\
T2 & $2,79 \mathrm{~b}$ & $0,18 \mathrm{~b}$ & $9,02 \mathrm{~b}$ & $1,22 \mathrm{a}$ & $0,41 \mathrm{a}$ & $0,13 \mathrm{~b}$ & $0,72 \mathrm{~b}$ & $8,34 \mathrm{~b}$ & $6,83 \mathrm{a}$ & $2,28 \mathrm{~b}$ \\
T3 & $3,04 \mathrm{~b}$ & $0,26 \mathrm{~b}$ & $11,57 \mathrm{~b}$ & $1,22 \mathrm{a}$ & $0,38 \mathrm{a}$ & $0,15 \mathrm{~b}$ & $0,96 \mathrm{~b}$ & $10,47 \mathrm{~b}$ & $6,21 \mathrm{a}$ & $3,26 \mathrm{~b}$ \\
T4 & $3,17 \mathrm{~b}$ & $0,23 \mathrm{~b}$ & $12,50 \mathrm{~b}$ & $0,99 \mathrm{a}$ & $0,36 \mathrm{a}$ & $0,14 \mathrm{~b}$ & $0,98 \mathrm{~b}$ & $8,84 \mathrm{~b}$ & $6,87 \mathrm{a}$ & $3,66 \mathrm{~b}$ \\
T5 & $4,58 \mathrm{a}$ & $0,37 \mathrm{a}$ & $18,33 \mathrm{a}$ & $1,30 \mathrm{a}$ & $0,51 \mathrm{a}$ & $0,20 \mathrm{a}$ & $1,28 \mathrm{a}$ & $13,43 \mathrm{a}$ & $6,67 \mathrm{a}$ & $6,72 \mathrm{a}$ \\
\hline F & $28,21 *$ & $19,36 *$ & $31,15 *$ & $14,63^{*}$ & $16,14 *$ & $24,22 *$ & $22,19 *$ & $14,30 *$ & $8,24 *$ & $24,22 *$ \\
Média & 2,44 & 0,185 & 9,08 & 0,86 & 0,3 & 0,113 & 0,7 & 7,5 & 5,36 & 2,8 \\
CV (\%) & 28,09 & 36,66 & 29,17 & 35,48 & 32,92 & 29,66 & 32,16 & 37,11 & 43,59 & 38,18 \\
\hline
\end{tabular}

*Médias seguidas pela mesma letra na coluna não diferem estatisticamente entre si pelo teste de Scott Knott (5\%) (means followed by the same letter in column do not differ significantly, Scott Knott 5\%).

\section{Conclusão}

A adubação com composto de esterco de galinha e cavaco de eucalipto como fonte de $\mathrm{N}$ proporciona maior produção e acúmulo de nutrientes em alface comparada com a adubação proveniente da uréia.

\section{Referências}

AGNOL, S. Esterco de galinha e seus benefícios. Rio Grande do Sul: Rural Atual, 2013. Disponível em:

http://ruralatual.blogspot.com.br/2013/08/ester co-de-galinha-e-seus-beneficios.html. Acesso em: 18 ago. 2017.
BARREIRA, L. P; SILVA, F. C. da; RODRIGUES, M. S.; MENDES FILHO, A. J.; GOMES, T. F.; GUEDES, R. E. Processo de compostagem e sistemas de trilhagem e compostagem de resíduos sólidos urbanos orgânicos. In: SILVA, F. C. da, PIRES A. M., RODRIGUES M. S., BARREIRA L. Gestão publica de resíduos sólidos urbanos: compostagem e interface Agro-Florestal. Botucatu: FEPAF, 2009. p. 53-68.

BENINNI, E. R. Y.; TAKAHASHI, H. W.; NEVES, C. S. V. J. Concentração e acúmulo de macronutrientes em alface cultivada em sistemas hidropônico e convencional. Semina: Ciências Agrárias, 
Londrina, v. 26, n. 3, p. 273-282, 2005.

https://doi.org/10.5433/1679-

$\underline{0359.2005 v 26 n 3 p 273}$

BRASIL. Ministério do Meio Ambiente. Conselho Nacional do Meio Ambiente. Resolução no 375/2006, de 29 de agosto de 2006. Define critérios e procedimentos, para o uso agrícola de lodos de esgoto gerados em estações de tratamento de esgoto sanitário e seus produtos derivados, e dá outras providências. Brasília: CONAMA, 2006. Disponível em: http://www2.mma.gov.br/port/conama/legiano1 .cfm?codlegitipo=3\&ano=todos. Acesso em: 10 out. 2006.

SANTOS, H. G. dos et al. Sistema brasileiro de classificação de solos. 2.ed. Brasília: Embrapa, 2013. 353 p.

KOO, R. C. J.; REESE, R. L. Influence of nitrogen, potassium, and irrigation on citrus fruit quality. In: INTERNATIONAL CITRUS CONGRESS, 1977, Riverside. Anais [...]. Riverside: International Society of Citriculture, 1977. p. 34-38.

LIMA, F. V. de; PEREIRA, J. R.; ALMEIDA, E. S. A. B. de; ARAUJO, V. L.; SOUZA JUNIOR, S. P. de. Avaliação sazonal do estado nutricional do algodoeiro herbáceo colorido BRS Rubi. Revista Brasileira de Ciências Agrárias. Recife, v. 9, n. 4, p. 500-505, 2014.

https://doi.org/10.5039/agraria.v9i4a3861

LOBO, T. F.; GRASSI FILHO, H. BULL, L. T.; KUMMER, A. C. B.; SOUZA, F. L. P. de. Desenvolvimento e nutrição do girassol com lodo de esgoto e nitrogênio. Revista em Agronegocio e Meio Ambiente, v. 12, n. 1, p. 173-193, 2019. https://doi.org/10.17765/2176-

9168.2019v12n1p173-193

LOBO, T. F.; GRASSI FILHO, H.; BULL, L. T.; MOREIRA, L. L. Q.; MARTINS, R. L. Efeito do manejo e de níveis de lodo de esgoto na fertilidade do solo após três aplicações. Bioscinse Journal, v. 29, n. 1, p. 288-296, 2013. https://doi.org/10.5380/rsa.v13i1.40859

LOBO, T. F.; GRASSI FILHO, H. Sewage Sludge on the development and nutricion of sunflower plants. Journal of Soil Science and Plant Nutrition. v. 9, n. 3, p. 245-255, 2009.
https://doi.org/10.4067/S0718-

$\underline{27912009000300007}$

MALAVOLTA, E.; VITTI G. C.; OLIVEIRA S. A. Avaliação do estado nutricional das plantas: princípios, métodos e técnicas de avaliação do estado nutricional. 2.ed. Piracicaba, SP: Editora Potafos, 1997. $319 \mathrm{p}$.

MELLO, S. C.; VITTI, G. C. Desenvolvimento do tomateiro e modificações nas propriedades químicas do solo em função da aplicação de resíduos orgânicos, sob cultivo protegido. Horticultura Brasileira, Brasília, v. 20, n. 2, p. 200-206, 2002. https://doi.org/10.1590/S0102$\underline{05362002000200017}$

PEIXOTO FILHO, J.; FREIRE, M. B. G. S.; FREIRE, F. J.; MIRANDA, M. F. A.; PESSOA, L. G. M.; KAMIMURA, K. M. Produtividade de alface com doses de esterco de frango, bovino e ovino em cultivos sucessivos. Revista Brasileira de Engenharia Agrícola e Ambiental, v. 17, n. 4, p. 419-424, 2013. https://doi.org/10.1590/S141543662013000400010.

QUEIROZ, A. A.; CRUVINEL, V. B.; FIGUEIREDO K. $M$. C. Produção de alface americana em função de fertilização com organo mineral. Enciclopédia Biosfera, v. 14, n. 25, p. 1053-1063, 2017. https://doi.org/10.18677/EnciBio 2017A84

RAIJ, B. Van.; CANTARELLA, H.; QUAGGIO, J. A.; FURLANI, A. M. C. Recomendações de adubação e calagem para o Estado de São Paulo. 2.ed. Campinas: IAC, 1997. 198 p. (IAC. Boletim Técnico, 100).

RESENDE, G. M. de; ALVARENGA, M. A. R.; EISHI, Y. S.; SOUZA, R. J. de; MOTA, J. H.; CARVALHO, J. G. de; RODIGUES JUNIOR, J. C. Rendimento e teores de macronutrientes em alface americana em função da dose de nitrogênio e molibdênio em cultivo de verão. Ciencia e Agrotecnologia, Lavras, v. 33, n. 1, p. 153-163, 2009.

https://doi.org/10.1590/S141370542009000100022

RODRIGUES, E. T.; CASALI, V. W. Resposta alface a adubação organica II Teores conteúdos e utilização de macronutrientes em cultivares. Revista ceres, Viçosa, v. 45, n. 261, p. 437-449, 1998. 
SANTIAGO, A. D.; ROSSETTO, R. Cana de açúcar: adubação orgânica. Brasília, DF: Agência Embrapa de Informação Tecnológica, 2009. 3 p.

SANTOS R. H. S; SILVA F; CASALI V. W. D; CONDE A. R. Efeito residual da adubação com composto orgânico sobre o crescimento. Pesquisa Agropecuaria Brasileira, v. 36, n. 1, p. 1395-1398, $2001 . \quad$ https://doi.org/10.1590/S0100204X2001001100010

SEDIYAMA, M. A. M.; MAGALHAES, I. de P. B.; VIDIGAL, S. M.; PINTO, C. L. de O.; CARDOSO, D. S. C. P.; FONSECA, M. C. M.; CARVALHO, I. P. L. de. Uso de fertilizantes orgânicos no cultivo de alface Americana (Lactura sativa L.) Kaiser. Revista Brasileira de Agropecuaria Sustentavel, v. 6, n. 2, p. 66-74, 2016.

https://doi.org/10.21206/rbas.v6i2.308

SHARMA, A. K.; SHARMA, A. M.; SHARMA, Y. $M$. Effect of irrigation, nitrogen and sulphur application on seed yield, quality and sulphur uptake by Indian mustard (Brassica juncea). Agriculture Science Digest, New Delhi, v. 14, n. 1, p. 63-67, 1994.

SILVA, F. A. M.; VILLAS BOAS, R. L.; SILVA, R. B. Resposta da alface à adubação nitrogenada com diferentes compostos orgânicos em dois ciclos sucessivos. Acta Scientiarum Agronomy, Maringá, v. 32, n. 1, p. 131-137, 2010.

https://doi.org/10.4025/actasciagron.v32i1.1340

SILVA, J. Pimenta: adubação orgânica. Brasília, DF: Ageitec, 2012. 2 p. Disponível em: http://www.agencia.cnptia.embrapa.br/gestor/pi menta/arvore/CONT000gn0k9bxa02wx5ok0liq1m q28xtscp.html. Acesso em: 22 out. 2017.

SOUZA, P. A.; NEGREIROS, M. Z.; MENEZES, J. B.; BEZERRA NETO, F.; SOUZA, G. L. F. M.; CARNEIRO, C. R.; QUEIROGA, R. C. F. Características químicas de alface cultivado sob efeito residual da adubação com composto orgânico. Horticultura Brasileira, v. 23, n. 3, p. 754-757, 2005.

https://doi.org/10.1590/S0102$\underline{05362005000300013}$

STEINER, F.; ECHER, M. de M.; GUIMARAES, V. F. Produção de alface piraroxa afetada pela adubação nitrogenada com fertilizante orgânico e mineral. Scientia Agraria Paranaensis, v. 11, n. 3, p. 77-83, 2012. https://doi.org/10.18188/19831471/sap.v11n3p77-83

TAIZ, L.; ZEIGER, E. Fisiologia vegetal. 5.ed. Porto alegre: Artmed, 2013. 